\title{
Manajemen Asuhan Kebidanan pada Ny "M" dengan Perdarahan Postpartum pada Tanggal 12 September s.d. 25 Oktober di RSUD Syekh Yusuf Gowa Tahun 2019
}

\author{
${ }^{1}$ Riski Sahid, ${ }^{2}$ Darmawansyih
}

\begin{abstract}
ABSTRAK
Pendahuluan Perdarahan Postpartum merupakan penyebab kematian terbesar pada ibu yang ditandai dengan kehilangan darah lebih dari $500 \mathrm{ml}$. Salah satu penyebab Perdarahan yaitu Retensio Plasenta. Retensio Plasenta adalah tertinggalnya Plasenta di dalam uterus 30 menit setelah bayi lahir yang menyebabkan Perdarahan dan perlu dilakukan tindakan segera seperti Manual Plasenta. Metode Karya tulis ilmiah ini bertujuan untuk melaksanakan Manajemen Asuhan Kebidanan pada Ibu dengan Perdarahan Postpartum di RSUD Syekh Yusuf Kabupaten Gowa Tahun 2019 sesuai dengan 7 langkah Varney dan SOAP. Hasil Penanganan yang diberikan kepada Ibu dengan Retensio Plasenta yakni dengan melakukan tindakan pemasangan infus RL + drips Oxytosin 2 ampl, kolaborasi dengan dokter untuk melakukan Manual plasenta, pemberian antibiotik, melakukan Pemeriksaan USG serta memantau Kala IV di RSUD Syekh Yusuf Kab. Gowa Tahun 2019 Kesimpulan dari studi kasus dengan Manajemen Asuhan Kebidanan 7 Langkah Varney dan SOAP yakni dari hari pertama sampai hari ketiga berlangsung normal yang ditandai dengan Plasenta dapat lahir tanpa ada sisa Plasenta, anemia teratasi, syok tidak terjadi, tanda-tanda infeksi tidak tampak serta tandatanda vital dalam batas normal. Maka dapat disimpulkan bahwa tidak ada kesenjangan antara tinjauan kasus dan tinjauan teori.
\end{abstract}

\section{ABSTRACT}

Introduction Postpartum hemorrhage is the most common cause of maternal mortality which is characterized by blood loss of more than $500 \mathrm{ml}$. One of the postpartum hemorrhage causes is a retained placenta, a condition where all or parts of the placenta remain in the uterus during the 30 minutes after the child delivery. In such condition, a manual placenta removal is urgently required. Method This paper was conducted to report the management of midwifery care for a patient with a postpartum hemorrhage in Syekh Yusuf Regional Public Hospital of Gowa Regency in 2019 by following the 7stage Varney and SOAP procedure. Result The midwifery care treatment arranged for the patient with a retained placenta include the administration of $R L+$ drips Oxytosin 2 ampl, a collaboration with the doctor who perform manual placenta removal, antibiotic administration, USG assessment, as well as the monitoring of the fourth stage of labor. Conclusion the management of midwifery care with the 7-stage Varney and SOAP documentation procedure from the first up to the third day of postpartum indicates that the patient's condition has been back to normal, as signified by the complete removal of the remaining placenta, well-treated anemia, prevented shock, the absence of infection indications, as well as the normal condition of vital signs. Thus, this research concludes that the case reports are aligned with the theories.

\author{
*Universitas Islam Negeri \\ Alauddin Makassar \\ *riskisahid97@gmail.com
}

\section{PENDAHULUAN}

Asuhan kebidanan masa nifas adalah penatalaksanaan asuhan yang diberikan pada pasien mulai dari saat setelah lahirnya bayi sampai dengan kembalinya tubuh dalam keadaan seperti sebelum hamil atau mendekati keadaan sebelum hamil. Periode masa nifas (puerperium) adalah periode waktu selama 6-8 minggu setelah persalinan. Proses ini dimulai setelah selesainya persalinan dan berakhir setelah alat-alat reproduksi kembali seperti keadaan sebelum hamil/tidak hamil sebagai akibat dari adanya perubahan fisiologi dan psikologi karena proses persalinan (Saleha 2013).

Peningkatan pelayanan serta pengawasan ibu hamil dapat mendeteksi lebih dini resiko persalinan (Yogi, Setiawan and Hastuti 2018). Adapun resiko yang dapat terjadi pada persalinan yaitu : terjadinya infeksi dan perdarahan postpartum (Maritalia 2012). 
Kematian ibu adalah kematian seorang wanita terjadi saat hamil, bersalin atau 42 hari setelah persalinan dengan penyebab yang berhubungan langsung atau tidak langsung terhadap persalinan. World Health Organization (WHO) memperkirakan 800 perempuan meninggal setiap harinya akibat komplikasi kehamilan dan proses kelahiran. Sekitar 99\% dari seluruh kematian ibu terjadi di negara berkembang. Sekitar 80\% kematian maternal merupakan akibat meningkatnya komplikasi selama kehamilan, persalinan dan setelah persalinan (World Health Organization (WHO) 2014).

Menurut Profil Kesehatan Indonesia tahun 2014 empat penyebab kematian ibu terbesar yaitu perdarahan 30,3\%, hipertensi dalam kehamilan (HDK) $27,1 \%$, infeksi 7,3\%, dan yang keempat meliputi kematian ibu tidak langsung seperti kondisi penyakit kanker, ginjal, jantung atau penyakit lain yang diderita ibu sebesar 35,3\% (Kemenkes RI 2014).

Perdarahan postpartum paling sering diartikan sebagai keadaan kehilangan darah lebih dari $500 \mathrm{ml}$ (Marmi 2011). Perdarahan postpartum adalah perdarahan yang berasal dari tempat implantasi plasenta, robekan pada jalan lahir, dan jaringan sekitarnya (Prawirohardjo 2014). Berdasarkan waktu terjadinya perdarahan postpartum dapat dibagi menjadi perdarahan primer dan perdarahan sekunder. Perdarahan primer adalah perdarahan yang terjadi dalam 24 jam pertama dan biasanya disebabkan oleh atonia uteri, robekan jalan lahir, sisa sebagian plasenta dan gangguan pembekuan darah. Perdarahan sekunder adalah perdarahan yang terjadi setelah 24 jam persalinan. Penyebab utama perdarahan postpartum sekunder biasanya disebabkan sisa plasenta (Satriyandari and Hariyati 2017).

Faktor predisposisi perdarahan postpartum adalah umur, paritas, status gizi, kelainan darah, kelahiran yang dibantu dengan alat (forcep, vacum), distensi uterus yang berlebihan karena hidramnion, bayi besar dan gemeli, induksi persalinan dan punya riwayat perdarahan postpartum. paska tindakan operasi vagina dan kelelahan ibu (prolong labour dan neglected labour) juga merupakan faktor predisposisi terjadinya perdarahan postpartum (Fitria and Puspitasari 2015).

Diberbagai negara paling sedikit seperempat dari seluruh kematian ibu disebabkan oleh pendarahan dalam waktu 24 jam setelah melahirkan, sebagian besar karena terlalu banyak mengeluarkan darah. Proporsinya berkisar antara kurang dari 10\% sampai hampir $60 \%$. Walaupun seorang perempuan bertahan hidup setelah mengalami pendarahan postpartum, namun perempuan akan menderita akibat kekurangan darah yang berat (anemia berat) dan akan mengalami masalah kesehatan yang berkepanjangan (Departemen Kesehatan RI 2008).

Angka kematian ibu di Kota Makassar menunjukkan penurunan dari 20,33/100.000 KH di Tahun 2014 menjadi 19,85/100.000 KH di tahun 2015, dimana terjadi 5 kematian ibu dari 22.181 kelahiran hidup di Kota Makassar. diantaranya 2 kasus disebabkan oleh perdarahan (Pemerintah Kota Makassar 2016).

Dari data rekam medik RSUD Syekh Yusuf Gowa pada tahun 2016, didapatkan jumlah ibu nifas sebanyak 1578 orang dan yang mengalami perdarahan postpartum sebanyak 57 orang. Pada tahun 2017 jumlah ibu nifas sebanyak 1638 orang dan yang mengalami perdarahan postpartum meningkat yaitu sebanyak 63 orang. Kemudian pada tahun 2018 jumlah ibu nifas sebanyak 1845 orang dan yang mengalami perdarahan postpartum yaitu sebanyak 4 orang. Pada tahun 2018 perdarahan postpartum di RSUD Syekh Yusuf mengalami penurunan. Angka ini menunjukkan adanya fluktuasi dari 3 tahun terakhir. Dari data rekam medik RSUD Syekh Yusuf Gowa, didapatkan, $50 \%$ pasien yang mengalami perdarahan postpartum berasal dari pasien rujukan. 


\section{METODE PENELITIAN}

Melaksanakan studi kasus pada Ny "M" dengan Perdarahan Postpartum pada tanggal 12 September s.d. 25 Oktober di RSUD Syekh Yusuf Gowa 2019 menggunakan pendekatan Manajemen Asuhan Kebidanan yang meliputi pengumpulan data, analisa dan perumusan diagnosa/masalah aktual dan potensial, perencanaan tindakan, evaluasi dan pendokumentasian dengan 7 langkah menurut Helen Varney dalam bentuk SOAP.

\section{HASIL PENELITIAN DAN PEMBAHASAN}

\section{Langkah I : Identifikasi Data Dasar}

Pada pengkajian didapatkan data subjektif Ny "M" dengan keluhan plasenta belum lahir kurang lebih 1 jam setelah bayi lahir. Manajemen aktif kala III berlangsung selama setengah jam setelah bayi lahir, dengan pemberian oxytocin ulang setelah pemberian oxytosin pertama. Namun tindakan tersebut tidak berhasil melahirkan plasenta.

Kala III persalinan merupakan kelanjutan dari kala I (kala pembukaan) dan kala II (kala pengeluaran bayi). Persalinan kala III dimulai setelah lahirnya bayi dan berakhir dengan lahirnya plasenta serta selaput ketuban. Manajemen aktif kala III adalah penatalaksanaan secara aktif kala III (pengeluaran aktif plasenta) untuk membantu menghindarkan terjadinya perdarahan postpartum. Segera dalam 1 menit setelah bayi lahir, suntikkan oxytosin secara intramuscular dan lakukan penegangan tali pusat terkendali. Pemberian oxytosin baik melalui intramuscular dan intravena dapat merangsang fundus uteri untuk berkontraksi dengan kuat dan efektif sehingga dapat membantu pelepasan plasenta dan mengurangi kehilangan darah (Asrinah, dkk, 2010).

Jika plasenta tidak lahir dalam waktu 15 menit, berikan oxytosin 10 IU secara intramuscular untuk dosis kedua. Kosongkan kandung kemih dan ulangi kembali penegangan tali pusat terkendali. Namun jika plasenta tidak lahir dalam setengah jam, maka lakukan rujukan. Tetapi apabila fasilitas kesehatan sulit dijangkau dan kemudian timbul perdarahan, sebaiknya digunakan tindakan Manual Plasenta (Asrinah, dkk, 2010).

Data lain yang ditemukan adalah data objektif pada Ny "M" yakni keadaan umum ibu lemah, kesadaran composmentis, tekanan darah $90 / 70 \mathrm{mmHg}$, nadi $86 \mathrm{x} / \mathrm{menit}$, suhu $36,8{ }^{\circ} \mathrm{C}$, pernafasan 24x/menit, Pengeluaran darah dari jalan lahir dalam jumlah banyak, Plasenta terlepas sebagian sehingga terjadi perdarahan dan mengganti underpad sebanyak 3 kali di Puskesmas Pallangga, maka dilakukan tindakan rujukan ke RSUD Syekh Yusuf, Gowa. Pengeluaran darah dalam jumlah banyak dan penurunan tanda-tanda vital merupakan tanda dari terjadinya retensio plasenta dan perdarahan postpartum. Retensio plasenta adalah tertinggalnya plasenta ataupun belum lahirnya plasenta hingga atau melebihi 30 menit setelah bayi lahir. pada retensio plasenta, sepanjang plasenta belum terlepas, maka tidak akan menimbulkan perdarahan (Prawirohardjo 2014).

Pada umumnya bila terdapat perdarahan yang lebih dari normal, apalagi telah menyebabkan perubahan tanda-tanda vital (seperti kesadaran menurun, pucat, limbung, berkeringat dingin, sesak nafas, serta tensi $<90 \mathrm{mmHg}$ dan nadi $>100 \mathrm{kali} / \mathrm{i}$ ), maka penanganan harus segera dilakukan (Prawirohardjo 2014).

Faktor penyebab utama perdarahan baik secara primer maupun sekunder adalah Usia, $<$ 20 tahun dan $>30$ tahun, grande-multipara, jarak persalinan pendek kurang dari 2 tahun, persalinan yang dilakukan tindakan, pertolongan kala uri sebelum waktunya, pertolongan persalinan oleh dukun, persalinan dengan tindakan paksa, pengeluaran plasenta tidak hati-hati (Mastiningsih, 2016). 
Pada pengkajian data subjektif Ny "M" berusia 34 tahun. Umur ibu termasuk salah satu faktor penyebab retensio plasenta. Menurut (Mastiningsih, 2016) Usia ibu hamil terlalu muda $(<20$ tahun) dan terlalu tua ( $>30$ tahun) mempunyai resiko yang lebih besar untuk melahirkan bayi kurang sehat. Hal ini dikarenakan pada umur 20 tahun, dari segi biologis fungsi organ reproduksi seorang wanita belum berkembang dengan sempurna untuk menerima keadaan janin dan segi psikis belum matang dalam menghadapi tuntutan beban moril, mental dan emosional, sedangkan pada umur diatas 30 tahun dan sering melahirkan, fungsi reproduksi seorang wanita sudah mengalami kemunduran atau degenerasi dibandingkan fungsi normal sehingga kemungkinan untuk terjadinya komplikasi postpartum terutama perdarahan lebih besar.

Hasil penelitian (Ramadhan, dkk, 2019) dengan 39 rekam medis yang memenuhi kriteria inklusi dan menjadi sampel penelitian terbagi atas 3 yaitu : Distribusi pasien berdasarkan klasifikasi Hemorrhagic Postpartum di RSUP Dr. Djamil Padang periode Januari 2016-September 2017 didapatkan Hemorrhagic Postpartum Primer sebanyak 31 orang dan Hemorrhagic Postpartum Sekunder sebanyak 8 orang.

Kemudian distribusi pasien berdasarkan faktor risiko di RSUP Dr. Djamil Padang periode Januari 2016-September 2017 didapatkan usia $<20$ tahun sebanyak 0 orang, usia 21 34 tahun sebanyak 27 orang, dan usia $>35$ tahun sebanyak 12 orang. Dan distribusi pasien berdasarkan etiologi di RSUP Dr. Djamil Padang periode Januari 2016-September 2017 didapatkan pada kasus atonia uteri sebanyak 6 orang, Retensio plasenta sebanyak 15 orang, sisa plasenta sebanyak 8 orang, robekan jalan lahir sebanyak 4 orang, inversion uteri sebanyak 4 orang, serta kelainan darah sebanyak 2 orang.

Maka dapat disimpulkan bahwa Hemorrhagic Postpartum primer pada periode januari 2016-September 2017 lebih tinggi dibandingkan dengan Hemorrhagic Postpartum sekunder dengan faktor usia 21-34 tahun dan yang menjadi penyebab terbanyak dari Hemorrhagic Postpartum adalah Retensio Plasenta. Berdasarkan pengkajian data objektif dan subjektif didapatkan bahwa tidak terdapat adanya kesenjangan antara tinjauan kasus dan tinjauan teori.

\section{Langkah II : Identifikasi Diagnosa/Masalah Aktual}

Pada Ny "M" didapatkan diagnosa utama yaitu perdarahan postpartum dengan retensio plasenta dan anemia. Terjadinya perdarahan postpartum pada Ny "M" disebabkan karena plasenta terlepas sebagian dari tempat implantasi dan laserasi jalan lahir. Perdarahan postpartum ini dapat mengakibatkan ibu mengalami kehilangan darah dalam jumlah banyak yang dapat mengakibatkan terjadinya anemia dan syok.

Pengeluaran darah pervaginam yang ditemukan pada $\mathrm{Ny}$ " $\mathrm{M}$ " sebanyak $\pm 350 \mathrm{cc}$. Berdasarkan teori mengatakan bahwa perdarahan postpartum adalah perdarahan yang melebihi $500 \mathrm{ml}$ setelah bayi lahir. Perdarahan primer adalah perdarahan yang terjadi dalam 24 jam pertama yang berasal dari tempat implantasi plasenta seperti atonia uteri, retensio plasenta dan rest plasenta, robekan pada jalan lahir, serta gangguan koagulasi (Satriyandari dan Hariyati, 2017).

Perdarahan postpartum yang disebabkan oleh retensio plasenta dapat mengakibatkan anemia. Pada pemeriksaan fisik serta pemeriksaan penunjang didapatkan Ny "M" mengalami anemia dengan kadar Hemoglobin 9,2 g/dl. Menurut (Risnawati dan Hanung, 2015) anemia dapat dibagi menjadi 3 bagian yaitu: anemia ringan ( $\mathrm{hb} 10-10,9 \mathrm{~g} / \mathrm{dl}$ ), anemia sedang ( 7-9,9 $\mathrm{g} / \mathrm{dl}$ ), anemia berat (hb kurang dari $7 \mathrm{~g} / \mathrm{dl}$ ). Penanganan retensio plasenta serta ruptur dapat menyebabkan perdarahan aktif yang perlu dilakukan tindakan segera serta persediaan transfusi. 
Anemia adalah suatu kondisi yang terjadi ketika jumlah sel darah merah (eritrosit) dan / atau jumlah haemoglobin yang ditemukan dalam sel-sel darah menurun di bawah normal. Sel darah merah dan hemoglobin yang terkandung di dalamnya diperlukan untuk transportasi dan pengiriman oksigen dari paru-paru ke seluruh tubuh. Tanpa kecukupan pasokan oksigen ke seluruh tubuh menyebabkan jaringan dan organ dapat terganggu. Ada 3 mekanisme utama tubuh yang menyebabkan anemia yaitu : penghancuran sel darah merah yang berlebihan, kehilangan darah (periode mestruasi berat atau persalinan), dan penurunan produksi sel darah merah (Proverwati, 2011).

Data lain ditemukan kontraksi uterus pada Ny "M" lemah, ruptur perineum tingkat II belum dijahit. Tampak dari vulva tali pusat terjelujur. TFU 1 jari di atas pusat. Tindakan Manual plasenta dan penjahitan ruptur tingkat II pada Ny "M" dilakukan di RSUD Syekh Yusuf, Gowa. Dimana, Manual Plasenta adalah tindakan untuk melepas plasenta secara manual (menggunakan tangan) dari tempat implantasinya dan kemudian melahirkannya keluar dari cavum uteri (Asrinah, dkk, 2010).

Sebelum diberikan tindakan Manual Plasenta, ditemukan ruptur. Pada Ny "M" didapatkan ruptur tingkat II dan telah dilakukan penjahitan tekhnik jelujur di RSUD Syekh Yusuf, Gowa. Menurut (Prawirohardjo 2014) ruptur perineum dapat terjadi hampir pada semua persalinan pertama dan tidak jarang pada kehamilan berikutnya. Ruptur perineum pada dasarnya tidak membahayakan jika mendapatkan penanganan dan perawatan yang tepat dan baik. Ruptur perineum yang tidak mendapatkan penanganan dan perawatan yang tepat dan baik, akan menyebabkan perdarahan yang hebat, infeksi hingga dapat menyebabkan kematian pada ibu Postpartum.

Menurut (Ramadhan, dkk, 2019) wanita yang mengalami anemia dalam persalinan dengan kadar hemoglobin $<11 \mathrm{~g} / \mathrm{dL}$ kondisinya akan dengan mudah terganggu meskipun mengeluarkan darah yang sedikit. Anemia dihubungkan dengan kelemahan yang dapat dianggap sebagai penyebab langsung perdarahan postpartum. Resiko perdarahan postpartum meningkat pada wanita bersalin dengan dimana uterus akan kekurangan oksigen, glukosa dan nutrisi esensial dan cenderung bekerja secara tidak efisien pada semua persalinan, hal inilah yang dapat menyebabkan perdarahan postpartum semakin meningkat. Anemia dalam kehamilan tidak hanya berdampak pada persalinan juga dapat berdampak pada masa nifas. Maka dapat disimpulkan bahwa tidak terdapat adanya kesenjangan antara tinjauan kasus dan tinjauan teori.

\section{Langkah III : Identifikasi Diagnosa/Masalah Potensial}

Pada Ny "M" berdasarkan masalah aktual didapatkan masalah potensial yaitu antisipasi terjadinya Syok Hemoragik atau Syok Hipovolemik. Dengan data penunjang adanya riwayat perdarahan, ibu tampak anemia, merasa lemas, pusing, dan berkeringat dingin serta terjadi penurunan tekanan darah. Menurut (Hikmah dan Yani, 2015) mengatakan bahwa perdarahan yang lebih dari normal dapat menyebabkan perubahan tanda vital, antara lain pasien mengeluh lemah, limbung, berkeringat dingin, menggigil hiperpnea, tekanan darah sistolik < $90 \mathrm{mmHg}$, denyut nadi $>100 /$ menit, kadar $\mathrm{Hb}<8 \mathrm{~g} / \mathrm{dL}$.

Perdarahan postpartum adalah perdarahan yang dapat besifat banyak, bergumpalgumpal atau terus merembes sedikit demi sedikit tanpa henti hingga menyebabkan syok. Syok Hemoragik ataua syok Hipovolemik adalah suatu syok yang terjadi akibat perdarahan. Hal ini menyebabkan gangguan sirkulasi darah ke dalam jaringan sehingga tidak dapat memenuhi kebutuhan oksigen dan nutrisi jaringan dan tidak mampu mengeluarkan hasil metabolisme (Prawirohardjo 2014).

Syok dapat terjadi karena adanya penurunan hebat volume plasma intravaskuler. Penurunan hebat volume plasma intravaskuler disebabkan oleh perdarahan. Pasokan darah 
yang kembali ke jantung akan berkurang, sehingga asupan oksigen ke jaringan atau sel tidak dapat terpenuhi. Sedangkan syok Hipovolemik dapat terjadi akibat berkurangnya volume plasma darah yang disebabkan oleh perdarahan yang hebat. Perdarahan yang hebat dapat disebabkan oleh adanya trauma pada organ-organ tubuh (frakur) yang disertai dengan luka atau luka langsung pada pembuluh darah (Hardisman, 2013). Maka dapat disimpulkan bahwa tidak terdapat adanya kesenjangan antara tinjauan kasus dan tinjauan teori.

\section{Langkah IV : Tindakan Segera/Kolaborasi}

Pada Ny "M" didapatkan data subjektif yaitu lemas, pusing dan berkeringat dingin, tekanan darah menurun, konjungtiva pucat, terdapat robekan jalan lahir serta pada pemeriksaan penunjang $\mathrm{Hb}$ tidak dalam batas normal yaitu 9,2 g/dl.

Menurut (Hardisman, 2013) Ciri-ciri Syok Hemoragik atau Syok Hipovolemik yaitu : terjadi penurunan tekanan darah, nadi, dan suhu tubuh secara drastis, pucat, lemas, serta pengeluaran keringat secara berlebihan,akral dingin, rasa nyeri pada dada, pusing, sesak, produksi urin berkurang, kuku dan bibir biru serta ibu mengalami kehilangan kesadaran.

Syok dapat terjadi akibat perdarahan yang menyebabkan gangguan sirkulasi darah ke dalam jaringan sehingga kebutuhan oksigen dan nutrisi jaringan tidak dapat terpenuhi (Prawirohardjo 2014). Dimana, Anemia dihubungkan dengan kelemahan yang dapat dianggap sebagai penyebab langsung perdarahan postpartum (Ramadhan, dkk, 2019). Anemia adalah suatu kondisi yang terjadi ketika jumlah sel darah merah (eritrosit) dan atau jumlah haemoglobin yang ditemukan dalam sel-sel darah menurun di bawah normal yaitu < $11 \mathrm{~g} / \mathrm{dL}$ (Proverwati, 2011).

Prinsip pertolongan pada perdarahan postpartum yaitu meminta pertolongan dan mencegah terjadinya syok hemoragik dengan mencari sumber perdarahan (Budiman dan Mayasari, 2017). Penanganan segera berkolaborasi dengan dokter dengan diagnosa perdarahan postpartum dengan restensio plasenta.Tindakan yang dilakukan yaitu Manual Plasenta, pemberian antibiotik serta pemberian obat oral (Prawirohardjo 2014). Maka dapat disimpulkan berdasarkan pengkajian pada $\mathrm{Ny}$ "M" yaitu tidak terdapat adanya kesenjangan antara tinjauan kasus dan tinjauan teori.

\section{Langkah V : Rencana Tindakan Asuhan Kebidanan}

Rencana tindakan yang dilakukan pada Ny "M" dengan retensio plasenta yaitu : Mejelaskan pada pasien tentang keadaan serta tindakan yang akan dilakukan dan lakukan informed consent. Mengajarkan ibu untuk melakukan masase fundus uteri dengan meletakkan tangan di atas perut ibu dan diputar searah jarum jam. Mengatur jumlah tetesan infuse RL + drips Oxytosin 20 iu 28 tetes/menit. Melakukan kateterisasi untuk memastikan kandung kemih kosong, dan memeriksa kontraksi uterus, tinggi fundus uterus (TFU), perdarahan serta pengeluaran lochea. Melakukan kolaborasi dengan dokter untuk penatalaksanaan Manual Plasenta serta pemberian antibiotik melalui Intravena dengan melakukan Skin Test. Menganjurkan ibu makan, minum serta beristirahat yang cukup. Lakukan penyuntikan secara intravena, drips antibiotik serta berikan obat oral. Berkolaborasi dengan dokter untuk pemeriksaan USG, melakukan pemantauan kala IV, memberikan Health Education, menjelaskan tentang ASI Ekslusif dan Alat Kontrasepsi.

Rencana tindakan dalam melakukan Manual Plasenta yakni : Berikan cariran IV : $\mathrm{NaCl}$ $0,9 \%$ atau RL dengan tetesan cepat dengan jarum berlubang besar. Siapkan peralatan untuk melakukan teknik Manual Plasenta yang harus dilakukan secara aseptic. Baringkan ibu terlentang dengan lutut ditekuk dan kedua kaki di tempat tidur (dorsal recumbent). Jelaskan pada ibu apa yang akan dilakukan. 
Lakukan teknik cuci tangan, kemudian pakai sarung tangan DTT. Masukkan tangan kanan dengan hati-hati, jaga agar jari tetap merapat dan melengkung mengikuti tali pusat sampai mencapat plasenta (pegang tali pusat dengan tangan kiri untuk membantu). Ketika tangan sudah mencapai plasenta, letakkan tangan kiri di atas fundus uteri agar uterus tidak naik. Kemudian carilah tepi plasenta yang terlepas menggunakan tangan kanan. Telapak tangan kanan menghadap ke atas lalu lakukan gerakan mengikis ke samping untuk melepaskan plasenta dari dinding uteri.

Jika plasenta sudah lahir, segera lakukan masase uterus, bila tidak ada kontraksi, lakukan langkah penanganan pada atonia uteri. Periksa plasenta dan selaputnya. Jika tidak lengkap, periksa cavum uteri dan keluarkan potongan plasenta yang tertinggal. Periksa robekan vagina, kemudian jahit robekan. Dekontaminasi sarung tangan ( sebelum dilepas) dan peralatan lain yang digunakan.Lepaskan dan rendam sarung tangan dan peralatan lainnya ke dalam larutan klorin 0,5\% selama 10 menit.Cuci tangan dengan metode 6 langkah di bawah air mengalir dengan menggunakan sabun dan keringkan dengan kain bersih. Jika tidak yakin plasenta dapat terlahir semua, rujuk ibu ke Rumah Sakit. Lakukan dokumentasi tindakan dan obat yang telah diberikan

Pada Ny "M" dengan diagnosa utama retensio plasenta dengan masalah aktual yaitu perdarahan postpartum dan anemia ringan serta masalah potensial yaitu Antisipasi Syok Hemoragik atau Syok Hipovolemik yang pada langkah ini bertujuan untuk mengatasi serta mencegah masalah yang telah terjadi dan berpotensi terjadi. Dimana, retensio plasenta adalah tertinggalnya plasenta ataupun belum lahirnya plasenta hingga atau melebihi 30 menit setelah bayi lahir sehingga harus dilakukan tindakan segera yakni Manual Plasenta (Prawirohardjo 2014). Berdasarkan hasil asuhan maka didapatkan tidak terdapat adanya kesenjangan antara tinjauan kasus dan tinjauan teori.

\section{Langkah VI : Implementasi Asuhan Kebidanan}

Pelaksanaan rencana asuhan kebidanan pada Ny "M" seperti pemasangan infuse RL drips Oxytosin, pengosongan kandung kemih, penjahitan teknik jelujur, telah dilakukan baik secara mandiri maupun kolaborasi dengan dokter dimulai dari tindakan Manual Plasenta, sampai pada pemberian terapi obat.

Pelaksanaan tindakan pada retensio plasenta menurut teori yaitu jika plasenta belum lahir dalam 15 menit setelah bayi lahir maka ulangi pelaksanaan aktif kala III dengan memberikan oksitosin secara IM dan teruskan peregangan tali pusat terkendali dengan hatihati. Teruskan melakukan penanganan aktif kala II selama 15 menit, dan jika plasenta masih belum lahir, lakukan peregangan tali pusat terkendali untuk terakhir kalinya. Jika plasenta msih belum lahir, dan ibu tidak mengalami perdarahan hebat, maka segera lakukan rujukan. Bila terjadi perdarahan, maka plasenta harus segera dilahirkan secara Manual Plasenta (Sulistyawati, 2009). Berdasarkan data tersebut, maka dapat disimpulkan bahwa tidak ada kesenjangan antara tinjauan kasus dan tinjauan teori.

\section{Langkah VII : Evaluasi Asuhan Kebidanan}

Pada Ny" 'H" dengan retensio plasenta didapatkan hasil yakni plasenta lahir dengan kesan tidak lengkap, telah dilakukan USG dan tidak ada sisa plasenta, kondisi umum baik, kesadaran composmentis, tanda-tanda vital dalam batas normal, infus dan pemberian obat telah dilakukan, kontraksi uterus baik teraba keras dan bundar, tinggi fundus uteri 1 jari bawah pusat, dan perdarahan hari $1 \pm 500 \mathrm{cc}$. Pada diagnosa potensial tidak terjadi syok Hemoragik atau syok Hipovolemik. 
Dari hasil evaluasi yang telah dilaksanakan pada Ny "M" menunjukkan bahwa hasil tindakan menyeluruh yang dilakukan berlangsung normal. Keadaan umum normal meliputi kesadaran composmentis serta tanda-tanda vital.

\section{KESIMPULAN DAN SARAN}

\section{A. Kesimpulan}

1. Berdasarkan studi kasus manajemen asuhan kebidanan pada Ny "M" dengan Perdarahan Postpartum di RSUD Syekh Yusuf Kabupaten Gowa dengan 7 Langkah Varney dapat disimpulkan bahwa:

a. Asuhan kebidanan pada Ny"M" dengan Perdarahan Postpartum di RSUD Syekh Yusuf Kabupaten Gowa dilakukan dengan pendekatan manajemen asuhan kebidanan yang dimulai dari identifikasi data dasar. Hasil dari identifikasi data dasar didapatkan Ny "M", umur 34 tahun, G1P0A0 dengan keluhan plasenta tidak lahir 1 jam setelah bayi lahir dan perdarahan $\pm 350 \mathrm{cc}$.

b. Telah dilaksanakan identifikasi diagnosa atau masalah aktual pada Ny"M" dengan perdarahan postpartum di RSUD Syekh Yusuf Kabupaten Gowa. Hasil dari identifikasi diagnosa atau masalah aktual didapatkan $\mathrm{Ny}$ "'M" mengalami perdarahan postpartum dengan retensio plasenta dan anemia.

c. Telah dilaksanakan identifikasi diagnosa atau masalah potensial pada Ny "M" dengan perdarahan postpartum di RSUD Syekh Yusuf Kabupaten Gowa. Hasil dari analisa dan interpretasi data aktual Ny "M" berpotensi mengalami syok Hemoragik atau syok Hypovolemik.

d. Telah dilaksanakan tindakan segera atau kolaborasi pada Ny' M" dengan perdarahan postpartum di RSUD Syekh Yusuf Kabupaten Gowa. Hasil tindakan segera/kolaborasi telah dilakukan penanganan retensio plasenta yaitu dengan melakukan manual plasenta.

e. Telah menetapkan rencana tindakan asuhan kebidanan pada Ny'M" dengan perdarahan postpartum di RSUD Syekh Yusuf Kabupaten Gowa. Dengan penatalaksanaan memantau perdarahan, kontrol involusio uteri, serta support menyusui.

f. Telah dilaksanakan tindakan asuhan kebidanan pada Ny"M" dengan perdarahan postpartum di RSUD Syekh Yusuf Kabupaten Gowa dengan hasil semua rencana tindakan dapat dilakukan secara menyeluruh tanpa adanya hambatan.

g. Telah dilaksanakan evaluasi hasil asuhan kebidanan pada Ny''M" dengan perdarahan postpartum di RSUD Syekh Yusuf Kabupaten Gowa dengan hasil evaluasi yakni tanda-tanda vital dalam keadaan normal, anemia teratasi dengan $\mathrm{Hb}: 9,2 \mathrm{~g} / \mathrm{dl}$, dan perdarahan telah berhenti.

2. Telah dilakukan pendokumentasian semua hasil dan tindakan asuhan kebidanan pada Ny"M" dengan perdarahan postpartum di RSUD Syekh Yusuf Kabupaten Gowa dalam bentuk 7 langkah varney dan SOAP.

\section{B. Saran}

Berdasarkan kesimpulan di atas maka penyusun akan menyampaikan beberapa saran yaitu : 
Bagi Peneliti

Diharapkan agar para peneliti dapat memberikan dukungan berupa support yang penuh, mampu berinteraksi dengan baik terhadap pasien dengan keadaan nyaman dan saling percaya. Serta dapat menerapkan nilai-nilai islami dan mengajarkan doa-doa dalam kelancaran persalinan hingga pada tahap masa nifas.

Bagi Profesi

Diharapkan agar para penyandang profesi dapat lebih meningkatkan pengambilan keputusan yang cepat dan tepat dalam memberikan asuhan kebidanan secara menyeluruh sesuai prosedur khususnya terhadap ibu postpartum dengan retensio plasenta sehingga dapat menghindari serta mengurangi resiko terjadinya komplikasi dari retensio plasenta.

Bagi Institusi

a. Pendidikan

Diharapkan dapat lebih meningkatkan mutu pendidikan secara teori terutama dalam melakukan praktik di kampus maupun di lahan agar mahasiswa dapat mengembangkan pengetahuan serta keterampilannya dalam memberikan asuhan serta dalam melakukan penatalaksaan yang sesuai dengan prosedur terutama pada kasus patologi.

b. Rumah Sakit

Mutu pelayanan rumah sakit sangat baik dari segi sarana dan prasarana. Namun untuk mewujudkan pelayanan kesehatan yang maksimal, diperlukan sistem yang cepat dan dapat dipermudah agar tidak terjadi keterlambatan penanganan dalam melakukan pelayanan sehingga kemungkinan terburuk seperti komplikasi dan bahkan kematian pada ibu dapat dicegah.

\section{DAFTAR PUSTAKA}

Ambarwati, Eny dan Diah Wulandari. (2008). Asuhan Kebidanan (Nifas). Jogjakarta: Mitra Cendekia. Asrinah, dkk. (2010). Asuhan Kebidanan Masa Persalinan. Yogyakarta: Graha ilmu.

Budiman dan Diana Mayasari. (2017). Perdarahan postpartum dini e.c retensio plasenta. J Medula Unila, 6-10.

Departemen Agama RI. (2012). Al-qur'an Tajwid dan Terjemahan. CV Diponegoro.

Departemen Kesehatan RI. (2008). Profil departemen kesehatan RI : Jakarta.

Fitria, Anisa dan Nunik Puspitasari. (2015). Hubungan dan faktor risiko partus lama riwayat perdarahan postpartum dan berat bayi lahir besar dengan kejadian postpartum. Jurnal Biometrika dan Kependudukan, 4 (2), 118-124.

Hardisman. (2013 ). Memahami patofisiologi dan aspek klinis syok hipovolemik : update dan penyegar. Jurnal Kesehatan Andalas, 2(3), 178-182.

Hikmah, Nurul dan Dian Puspita Yani. (2015). Gambaran hemoragic postpartum pada ibu bersalin dengan kejadian anemia di ruang ponek RSUD Kabupaten Jombang. Journal Edu Health, 5 (2), 142-147.

Insani, Aldina, dkk. (2016). "Berfikir Kritis" Dasar bidan dalam manajemen asuhan kebidanan. 21-30.

Kemenkes RI. (2014). Profil kesehatan Indonesia. Kementrian Kesehatan RI, Jakarta.

Mangkuji dan Betty. (2013). Asuhan Kebidanan 7 Langkah Varney SOAP. Jakarta: EGC.

Maritalia, Dewi. (2012). Asuhan Kebidanan Nifas dan Menyusui. Yogyakarta: Pustaka Pelajar.

Marmi. (2011). Asuhan Kebidanan Pada Masa Nifas "puerperium care". Yogyakarta: Pustaka Pelajar.

Mastiningsih, Putu. (2016). Rest plasenta pada ibu nifas P1A1 6 jam postpartum di ruang bersalin RSUD Wangaya. Journal Dunia Kesehatan, 5(2), 76-86.

Norvadewi. (2014). Profesionalisme bisnis dalam islam. Mazahib, 8 (2), 175-188.

Nurjanah, Siti, dkk. (2013). Asuhan Kebidanan Postpartum Dilengkapi dengan Asuhan Kebidanan Post Sectio Caesarea. Bandung: PT Refika Aditama. 
Pemerintah Kota Makassar. (2016). Profil Kesehatan Kota Makassar. Kota Makassar.

Prawirohardjo, Sarwono. (2014). Ilmu Kebidanan Sarwono Prawirohardjo. Jakarta: PT. Bina Pustaka. Proverwati, Atikah. (2011). Anemia dan Anemia Kehamilan. Yogyakarta: Nuha medika.

Ramadhan, Jihan, dkk. (2019). Profil pasien hemoragic postpartum di RSUP Dr.M Djamil Padang. Jurnal Kesehatan Andalas, 46-53.

Rekam Medik. (2018). Rumah Sakit Umum daerah Syekh Yusuf Gowa.

Risnawati, Indah dan Allania Hanung. (2015). Dampak anemia kehamilan terhadap perdarahan postpartum. Stikkes Muhammadiyah Kudus, 6(3), 57-67.

Saleha, Sitti. (2013). Asuhan Kebidanan pada Masa Nifas. Jakarta: Salemba Medika.

Sari, Evin dan Sitti Khotimah. (2018). Asuhan Kebidanan Masa Nifas dan Menyusui. Bogor : In Media.

Satriyandari, Yekti dan Nena Riski Hariyati. (2017). Faktor-faktor yang mempengaruhi kejadian postpartum. Journal of Health Studies, 1 (1), 49-64.

Setiawan, Satria dan Ratna Dewi Puspitasari. (2017). P4A0 perdarahan pasca persalian ec inversio uteri dan syok hipovolemik dengan histerektomi. JMedula Unila, 7 (2), 128-132.

Shihab, M Quraish. (2002). Tafsir Al-Misbah. Jakarta: Lentera Hati.

Sulistyawati, Ari. (2009). Buku Ajar asuhan Kebidanan pada Ibu Nifas. Yogyakarta: CV Andi Offset.

Windu, Dewa. (2016). Tanda bahaya serta penatalaksanaan postpartum. ISM, 3 (1), 9-18.

Woordward, Vivien, dkk. (2005). Managing Emergencies in Community Settings. English: Palgrave Macmillan.

World Health Organization (WHO). (2014). WHO, UNICEF, UNFPA, The WorldBank. Trends in maternal mortality: 1990 to 2013.

Yogi, Etika, dkk. (2018). Hubungan paritas dengan kejadian perdarahan pada ibu post partum di BPS Ny.N di Desa Klagen Serut Kecamatan Jiwan Madiun. Jurnal Delima Harapan, 5 (2), 39-34. 